\title{
Development of porous alumina membranes for treatment of textile effluent
}

\author{
Késia Karina O.S. Silva ${ }^{\mathrm{a}}$, Carlos A. Paskocimas ${ }^{\mathrm{b}}$, Fernando R. Oliveira ${ }^{\mathrm{a}}$, \\ José H.O. Nascimento ${ }^{\mathrm{a}}$, Andrea Zille ${ }^{\mathrm{c}, *}$ \\ ${ }^{a}$ Department of Textile Engineering, Federal University of Rio Grande do Norte, Av. Salgado Filho, 3000, Lagoa Nova, Natal, RN \\ 59078 970, Brazil, Tel. +55 849818 2142; email: kesiasouto@hotmail.com (K.K.O.S. Silva), Tel. +55 8498144994 ; \\ email: fernandomoc@hotmail.com (F.R. Oliveira), Tel. +55 849158 3301; email: heribertoo@ufrnet.br (J.H.O. Nascimento) \\ ${ }^{b}$ Department of Materials Science and Engineering, Federal University of Rio Grande do Norte, Av. Salgado Filho, 3000, Lagoa \\ Nova, Natal, RN 59078 970, Brazil, Tel.+55 849193 6172; email: paskocimas@uol.com.br \\ ${ }^{c} 2 \mathrm{C} 2 \mathrm{~T}$ - Centro de Ciência e Tecnologia Têxtil, Departamento de Engenharia Têxtil, Universidade do Minho 4800-058, Guimarães, \\ Portugal, Tel. +351 253510285; email: azille@2c2t.uminho.pt
}

Received 15 October 2014; Accepted 20 January 2015

\begin{abstract}
Ceramic porous membranes sintered at two different temperature using polyvinyl alcohol and ethylene glycol as binders, and composed of two types of $\alpha$-alumina with different particle sizes were investigated for the microfiltration of a textile effluent containing indigo dye, auxiliaries, heavy metals, oils, and solids. The physicochemical properties of the membranes and effluent were evaluated. X-ray diffraction, energy dispersive $\mathrm{X}$-ray fluorescence spectroscopy, differential scanning calorimetry, and thermogravimetric analysis confirm that the thin membrane is composed of high crystalline and pure $\alpha$-alumina. Scanning electron microscopy observation indicates that the membranes have smooth porous surface making it suitable for microfiltration applications. The membrane sintered at $1,450^{\circ} \mathrm{C}$ exhibited higher water absorption (WA) and apparent porosity than that sintered at $1,475^{\circ} \mathrm{C}$. The apparent specific gravity and flexural strength are in inverse correlation with the WA due to the enhanced densification of the membranes. The filtered effluent was evaluated using a membrane with an average pore size of $0.4 \mu \mathrm{m}$ and a total porosity of $29.6 \%$. The average values of rejection were $90 \%$ for color, $93 \%$ for suspended solids, $95 \%$ for turbidity, $60 \%$ for metals, and $73 \%$ for chemical oxygen demand. These results demonstrate that low-cost ceramic alumina membranes are a very promising advanced treatment for textile industrial effluents.
\end{abstract}

Keywords: Ceramic; Alumina; Porous membranes; Textile effluent; Filtration

\section{Introduction}

Textile industry is one of the most polluting industries not only due to the high water consumption, but

*Corresponding author. also due to the wide variety of substrates and chemicals used in different process steps [1]. These processes generate large volumes of strongly colored wastewaters with high load of toxic organic and inorganic compounds [2]. Nowadays, due to the increasing environmental requirements, textile industry needs to

Presented at the International Congress on Water, Waste and Energy Management 16-18 July 2014, Porto, Portugal

1944-3994/1944-3986 @ 2015 Balaban Desalination Publications. All rights reserved. 
adopt a sustainable approach, where at least $90 \%$ of the used chemicals are recycled or treated before their release in the environment [3]. Currently, textile wastewater treatments mainly involve physical and/or chemical processes as membrane filtration, coagulation/ flocculation, precipitation, flotation, adsorption, ion exchange, ion pair extraction, ultrasonic mineralization, electrolysis, chemical reduction, and advanced chemical oxidation [4-6]. Moreover, color removal by biological and conventional treatment, such as ozonation, bleaching, UV, and electrochemical techniques was found to be inadequate because most textile dyes have recalcitrant complex aromatic molecular structures [7]. Membrane-based separation processes have gradually become an attractive alternative to the conventional separation processes in the treatment of wastewater, since their application allow high removal efficiencies and also provide recovery and recycling of water and chemicals [8]. Ceramic membranes display several advantages over organic membranes, such as an easy control of the pore size, higher durability, and efficiency. They can be applied in the presence of organic solvents at high temperatures (up to $600^{\circ} \mathrm{C}$ ) and in a wide range of $\mathrm{pH}$ due to their good thermal resistance, mechanical strength, and chemical inertia [9-11].

Microfiltration processes using porous membranes were increasingly exploited in recent years to separate suspended particles with diameters between 0.1 and $10 \mu \mathrm{m}$, due to the relatively higher flux and low cost [12]. These types of membranes are generally not suitable for wastewater reuse, as the membrane pore size is too large to reject small dye molecules [13]. However, this problem can be solved using by a proper pretreatment technique that allow high removal efficiencies without the high fouling resistance and low permeates flux of the more expensive ultrafiltration (UF) membranes [14].

The main objective of this study was to evaluate the efficiency of microfiltration ceramic membranes composed of two types of $\alpha$-alumina sintered at different temperatures for indigo dye separation of textile industry effluents. Indigo is one of the most used dyes in textile industry, generating a large amount of wastewater. It is mainly used as a dye for cotton yarn for the production of denim cloth for blue jeans. It is a darkblue compound having melting point of about $390^{\circ} \mathrm{C}$, insoluble in water, alcohol or ether, but soluble in chloroform, nitrobenzene, or concentrated sulfuric acid [15]. Ceramic membranes were characterized in relation to pore size, tangential flux, and physicochemical characteristics. The textile effluent was pretreated and characterized, before and after a dead-end filtration, for metals, color, chemical oxygen demand (COD), suspended solids, and turbidity (TU) reduction.

\section{Materials and methods}

\subsection{Materials}

A reactive $\alpha$-alumina $\left(\mathrm{Al}_{2} \mathrm{O}_{3}\right)$ (Alcoa-CT $3000 \mathrm{SG}$, USA, $\left.\mathrm{d}_{50}=0.5 \mu \mathrm{m}\right)$ named $\mathrm{A} 1$ and a calcined $\alpha$-alumina (A2-G, Alcoa, USA, $\mathrm{d}_{50}=4 \mu \mathrm{m}$ ) named A2 were used in this work. The alumina blends were unbundled and screened in a 200-mesh sieve before processing. The filtered indigo (denim) effluent was collected from a textile company in the industrial district of São Gonçalo do Amarante, RN, Brazil. Before filtration, the raw effluent was decanted, oxygenated, cooled, and pretreated by adding sulfuric acid in order to reduce the $\mathrm{pH}$ (from 10.6 to 4.5), calcium hydroxide to optimize charge destabilization, a cationic coagulant, and an anionic polymeric flocculant. All the other reagents were of analytical grade purchased from Sigma-Aldrich, St. Louis, MO, USA, and used without further purification.

\subsection{Membrane preparation}

Ceramic microfiltration membranes were prepared sintering the alumina powders mixed with binders. The alumina paste was produced in an aqueous solution of polyvinyl alcohol (PVA) and ethylene glycol (EG) as binders in the proportion 70:30 (Vetec Química Fina LTDA, Brazil). PVA was dissolved at $65^{\circ} \mathrm{C}$ for $30 \mathrm{~min}$. Then, EG was slowly added to PVA solution under continuous stirring for $60 \mathrm{~min}$. A1 and A2 alumina were mixed in the proportion 3:1 (Granulometry $\mathrm{D}_{50} 1.8 \mu \mathrm{m}$ and $\left.\mathrm{D}_{\mathrm{M}} 2.3 \mu \mathrm{m}\right)$. A small amount of sodium silicate $\left(\mathrm{Na}_{2} \mathrm{SiO}_{3}\right.$ ) (Pernambuco Química, Brazil) was added to the suspensions to avoid flocculation and to adjust density. The obtained ceramic paste was dried for $24 \mathrm{~h}$ at $105^{\circ} \mathrm{C}$ and mixed in a stainless steel ball mill for $30 \mathrm{~min}$. The resulting powder was screened in a 48-mesh standard sieve. A fixed amount of pre-wetted screened powder ( $7 \mathrm{~g}$ including $10 \%$ of water) was uniaxially pressed at $37.5 \mathrm{MPa}$ for $20 \mathrm{~s}$ in a stainless steel mold to obtain a $5 \mathrm{~cm}$ circular-shaped disk sample. Then, the samples were dried at room temperature for $24 \mathrm{~h}$, and then gradually dried for $24 \mathrm{~h}$ in hot air oven from 100 to $200^{\circ} \mathrm{C}$. This drying process ensures maximum moisture removal without thermal stresses. The dried samples were placed vertically in the grooves of insulation bricks to ensure uniform sintering. The sintering process was performed in a muffle furnace at 1,350, 1,450, and $1,475^{\circ} \mathrm{C}$ for $2 \mathrm{~h}$ with a heating rate of $3^{\circ} \mathrm{C} \mathrm{min}{ }^{-1}$ from 32 to $500^{\circ} \mathrm{C}$ and $5^{\circ} \mathrm{C} \mathrm{min}^{-1}$ from 500 to $1,475^{\circ} \mathrm{C}$, and a cooling rate of $10^{\circ} \mathrm{C} \mathrm{min}{ }^{-1}$ from 1,475 to $32^{\circ} \mathrm{C}$. The rate of heating in the furnace was kept low to minimize bending. The cooling rate was kept low to reduce 
cooling stress and to achieve homogeneity of the microstructure. It also improves the porosity of the support due to the formation of large grain.

\subsection{Diffusion properties}

Water absorption percentage (WA), apparent specific gravity (SG), and porosity (AP) was evaluated according to the Brazilian national standard NBR 13.818/97, NBR 13.818/9, and NBR 13.818/97, respectively. Particle size (AG) was confirmed by means of laser granulometry analysis (CILAS, model 1180). Samples were screened in a $100 \mathrm{~nm}$ mesh sieve and sonicated in water for $60 \mathrm{~s}$. Mercury intrusion experiments were performed over a wide range of pressures from 50 to 8,000 psi $\left(1 \mathrm{psi}=6.895 \times 10^{-3} \mathrm{MPa}\right)$ in a Quantachrome Poremaster 33 (Quantachrome, Boynton Beach, USA) instrument. Mercury surface tension and intrusion contact angle were set at $0.480 \mathrm{~N} \mathrm{~m}^{-1}$ and $140^{\circ}$, respectively. Data acquisition was performed in continuous scanning mode, in which the rate of pressurization is automatically controlled by the motor speed of the pressure generator system.

\subsection{Mechanical properties}

Three-point flexural strength (FS) was performed at room temperature on a Shimadzu AG-X $300 \mathrm{kN}$ universal testing machine with a constant strain rate of $0.1 \mathrm{~mm} \mathrm{~min}^{-1}$. An extensometer with $40 \mathrm{~mm}$ gage length was used. Shrinkage (DL) was evaluated using a DIL 402 PC dilatometer equipment (Netzsch $\mathrm{GmbH}$, Selb, Germany) in the range of $25-1,500^{\circ} \mathrm{C}$, under a constant heating rate of $5^{\circ} \mathrm{C} \mathrm{min}^{-1}$ in an argon atmosphere with a flow rate of $100 \mathrm{ml} \mathrm{min}^{-1}$.

\subsection{X-ray diffraction}

X-ray diffraction (XRD) measurements were taken on a diffractometer Shimadzu (XRD 7000), equipped with a $\mathrm{Cu}-\mathrm{K} \alpha$ tube, and a secondary monochromator. The goniometer used was a Siemens D500 and the detector was the scintillator ( $\mathrm{NaI}$ and $\mathrm{Tl}$ ). The measures were carried out at room temperature in continuous mode with a scan speed of $2^{\circ} \mathrm{min}^{-1}$, covering the angles $2 \theta$ between 5 and $80^{\circ}$. The results were analyzed using the PMGR software (Shimadzu). The crystalline phase was compared with the JCPDS data-set ("Joint Committee on Powder Diffraction Standards").

\subsection{Energy dispersive X-ray fluorescence spectroscopy}

The elemental compositions were determined by EDXRF, using a EDX-720 spectrometer (Shimadzu,
Japan) under vacuum mode for precise measurement. X-ray spectra were collected using a $\mathrm{Si}(\mathrm{Li})$ detector with a Rh anode and lit 100, PET, Ge and OVO 55 crystals, spectroscopy amplifier, HV bias supply, and a multichannel analyzer, including the analog to digital converter. The energy resolution of the spectrometer is $160 \mathrm{eV}$ at $5.9 \mathrm{keV}$. For this study, $5.9 \mathrm{keV}$ photons emitted from ${ }^{55} \mathrm{Fe}$, and $59.5 \mathrm{keV}$ photons emitted from ${ }^{241} \mathrm{Am}$ radioactive source were used to excite the characteristic X-rays of various elements present in the samples covering almost all the elements in the periodic table that range from $\mathrm{Na}_{11}$ to $\mathrm{U}_{92}$.

\subsection{Thermogravimetric and differential scanning calorimetry analyses}

The Thermogravimetric (TGA) and differential scanning calorimetry (DSC) analyses were carried in a STA 449 F3 (Netzsch GmbH, Selb, Germany). The analyses were performed in the range of $25-1,500^{\circ} \mathrm{C}$, under an argon atmosphere with a flow rate of $70 \mathrm{ml} \mathrm{min}{ }^{-1}$ and a heating rate of $10^{\circ} \mathrm{C} \mathrm{min}$. Data were plotted as weight loss (\%) vs. temperature for TGA and as heat flow vs. temperature for DSC. The temperature at which the RPS starts to decompose was selected as the upper limit for DSC.

\subsection{Scanning electron microscopy}

Morphological analyses of alumina membranes were carried out with an analytical scanning electron microscope SUPERSCAN SSX-550 (Shimadzu, Japan). Secondary electron images were performed with an acceleration voltage between 5 and $10 \mathrm{kV}$. Backscattering electron images were made with an acceleration voltage of $15 \mathrm{kV}$. Samples were covered with a film of $\mathrm{Au}-\mathrm{Pd}$ (80-20 weight \%) in a high-resolution sputter coater, 208HR Cressington Company, coupled to with a MTM-20 Cressington High Resolution Thickness Controller.

\subsection{Effluent Characterization}

Total suspended and dissolved solids (TDS), and total content of oil and grease were determined using the gravimetric method. The $\mathrm{pH}$ and temperature $(T)$ have been measured with a $\mathrm{pH} / \mathrm{mV}$ meter THERMOSTAR, A212 model. Turbidity TU was measured by a Digimed turbidimeter HDM-TU type. Effluent coloration was determined spectrophotometrically on an UV-vis spectrophotometer (HACH, DR2000) after and before treatment at $420 \mathrm{~nm}$. Total phosphorous (TP) 
was calculated by colorimetric method. Metal content analysis $(\mathrm{Cd}, \mathrm{Pb}, \mathrm{Zn}, \mathrm{Fe}, \mathrm{Cr}, \mathrm{Cu}, \mathrm{Mn}$, and $\mathrm{Ni}$ ) was performed by atomic absorption spectroscopy (VARIAN, model 50B). COD was performed according to standard method.

\subsection{Microfiltration test}

Effluents were microfiltered with a vacuum pump (Tecnal, TE-058) working at $600 \mathrm{~mm} \mathrm{Hg}(78,92 \mathrm{kPa})$ in a laboratory pilot-scale setup, using the membrane sintered at $1,450^{\circ} \mathrm{C}$ for $2 \mathrm{~h}$. A Sterfil ${ }^{\circledR}$ polysulfone filtration system (Millipore) was also used. The filtration cell allows testing membranes with a $5 \mathrm{~cm}$ diameter and a working volume of $250 \mathrm{ml}$. The solution in the chamber was stirred by a Teflon-coated magnetic bar at $300 \mathrm{rpm}$. All experiments were carried at $25^{\circ} \mathrm{C}$. Each experiment was performed in triplicate. The $\mathrm{t}$-Student test was used to test the statistical significance of the attained results when $p<0.001$.

\section{Results and discussion}

The primary goal in sintering is to impart sufficient mechanical strength to the membranes while maintaining sufficient permeability. Sintering stress damages do not occur in $\alpha$-alumina at temperatures up to $1,250^{\circ} \mathrm{C}$, however for higher temperature, a careful control of this process is crucial, especially when the membranes containing different materials such as PVA and EG. An initial set of tests was performed to evaluate the main properties of the membranes sintered under different condition of time and temperature $\left(1,350^{\circ} \mathrm{C}\right.$ at $2 \mathrm{~h}, 1,450^{\circ} \mathrm{C}$ at $30 \mathrm{~min}$, and $2 \mathrm{~h}$, $1,475^{\circ} \mathrm{C}$ at $30 \mathrm{~min}$ and $2 \mathrm{~h}$ ). A clear growth in density was observed increasing the sintering temperature up to $1,475^{\circ} \mathrm{C}$. At higher sintering temperatures, a decrease in density was observed (data not shown) because of the excessive increase of the average grain size at sintering temperatures higher than $1,500^{\circ} \mathrm{C}$. Conversely, the membranes sintered at $1,350^{\circ} \mathrm{C}$ showed a three-point FS; three times lower than the results obtained at higher temperature, probably because alumina particles partially aggregated in its original state. When the sintering temperature reached $1,450^{\circ} \mathrm{C}$, a more dense-packed microstructure with the concomitant growth of the alumina grains can be observed. However, a sintering time of $30 \mathrm{~min}$ is not sufficient to reach an acceptable mechanical resistance. Sintering at $1,350^{\circ} \mathrm{C}$ or at higher temperatures for $30 \mathrm{~min}$ leads to membranes with low mechanical strength, large pore size, and high value of mercury intrusion porosity for membranes. The best results in term of water adsorption, porosity, and mechanical resistance were obtained using a sintering time of $2 \mathrm{~h}$ for the temperatures at 1,450 and $1,475^{\circ} \mathrm{C}$. So, the subsequent test was performed solely on the membranes sintered at these two temperatures that despite the sintering temperature proximity have shown significant differences.

The durability of a membrane, beside its mechanical strength, also depends on WA behavior. Water absorption, which is the mass of moisture in the pores as a fraction of the mass of the sintered membrane, is an effective indicator of the quality of porous ceramic filters. The membrane sintered at $1,450^{\circ} \mathrm{C}$ exhibits higher WA (17.1\%) than the membrane sintered at $1,475^{\circ} \mathrm{C}(15.3 \%)$. The effect of high sintering temperatures on WA is attributed to the completion of the $\alpha$-alumina crystallization process that reduces the open pores in the membrane [16]. The results of AP show the same trend decreasing from 44.7 to $40.2 \%$ with the increase in sintering temperature (Table 1). The SG seems to be in inverse correlation with the water absorption. During the crystallization process, the distance between the particles in the sinter should be decreased with the increase of the temperature. However, only minor difference can be observed due to the limit of detection of the used methodology [17]. Nevertheless, the value of $2.6 \mathrm{~g} \mathrm{~cm}^{-3}$ is in accordance with the theoretical density of the formulation calculated from the ideal chemical composition. As expected, high temperatures have a positive effect on FS resulting in superior strengths. The porous membranes exhibits three-point FS values of $35 \mathrm{Mpa}$ at $1,450^{\circ} \mathrm{C}$ and $37 \mathrm{Mpa}$ at $1,475^{\circ} \mathrm{C}$. The slight improvement on the FS is ascribed to the enhanced densification of the porous alumina ceramic membranes [18].

The XRD profile of powder alumina and sintered membranes exhibit sharp characteristic peaks of purephase $\alpha$-alumina (Fig. 1). The XRD spectra of the alumina in different configurations show identical XRD patterns. The presence of a sharp $\alpha$-alumina peak is indicative of high crystallinity and relatively thin membrane structure [19]. A slight increase in the relative intensity of $\alpha$-alumina peak in the XRD spectra of the membranes is attributed to the texturing effect under pressure [20]. The diffraction patterns also reveal the randomly oriented nature of the crystals.

Scanning electron microscopy (SEM) analysis indicates the absence of pinholes and cracks on the membrane structure making it suitable for microfiltration applications. Fig. 2 illustrates SEM pictures of the membrane sintered at the two tested temperatures. The porosity of the membrane decreases with the increase in sintering temperature as confirmed by the mercury intrusion porosity results. The ceramic 
Table 1

Properties of the $\alpha$-alumina composite membrane sintered at different temperatures and times. Data are means \pm standard deviations $(n=3)$

\begin{tabular}{|c|c|c|c|c|c|}
\hline & \multirow{2}{*}{$\begin{array}{l}1,350^{\circ} \mathrm{C} \\
2 \mathrm{~h}\end{array}$} & \multicolumn{2}{|l|}{$1,450^{\circ} \mathrm{C}$} & \multicolumn{2}{|l|}{$1,475^{\circ} \mathrm{C}$} \\
\hline & & $0.5 \mathrm{~h}$ & $2 \mathrm{~h}$ & $0.5 \mathrm{~h}$ & $2 \mathrm{~h}$ \\
\hline BL (\%) & $2.5 \pm 0.4$ & $4.7 \pm 0.6$ & $4.6 \pm 0.6$ & $4.0 \pm 0.4$ & $5.4 \pm 0.6$ \\
\hline TF (MPa) & $12.4 \pm 0.8$ & $25.5 \pm 1.1$ & $35.3 \pm 0.9$ & $32.8 \pm 1.2$ & $37.8 \pm 1.8$ \\
\hline $\mathrm{MP}(\%)$ & $34.1 \pm 0.6$ & $26.8 \pm 0.4$ & $29.7 \pm 0.5$ & $25.3 \pm 0.4$ & $25.5 \pm 0.4$ \\
\hline $\mathrm{PD}(\mu \mathrm{m})$ & $0.3-1.6$ & $0.1-3.0$ & $0.025-2.0$ & $0.35-2.0$ & $0.025-1.7$ \\
\hline $\mathrm{PA}(\mu \mathrm{m})$ & $0.7 \pm 0.01$ & $0.7 \pm 0.01$ & $0.4 \pm 0.01$ & $0.8 \pm 0.01$ & $0.4 \pm 0.01$ \\
\hline WA $(\%)$ & $21.0 \pm 1.2$ & $18.2 \pm 0.8$ & $17.1 \pm 1.1$ & $18.4 \pm 0.9$ & $15.3 \pm 0.9$ \\
\hline $\mathrm{AP}(\%)$ & $44.3 \pm 1.8$ & $44.1 \pm 2.0$ & $44.7 \pm 2.1$ & $41.6 \pm 1.8$ & $40.2 \pm 1.9$ \\
\hline $\mathrm{AG}\left(\mathrm{g} \mathrm{cm}^{-3}\right)$ & $2.3 \pm 0.3$ & $2.5 \pm 0.3$ & $2.6 \pm 0.3$ & $2.3 \pm 0.3$ & $2.6 \pm 0.3$ \\
\hline
\end{tabular}

Notes: (BL) Burning linear retraction; (TF) three-point flexural strength; (MP) mercury intrusion porosity; (PD) pore distribution; (PA) pore average; (WA) water absorption; (AP) apparent porosity; and (AG) apparent specific gravity.

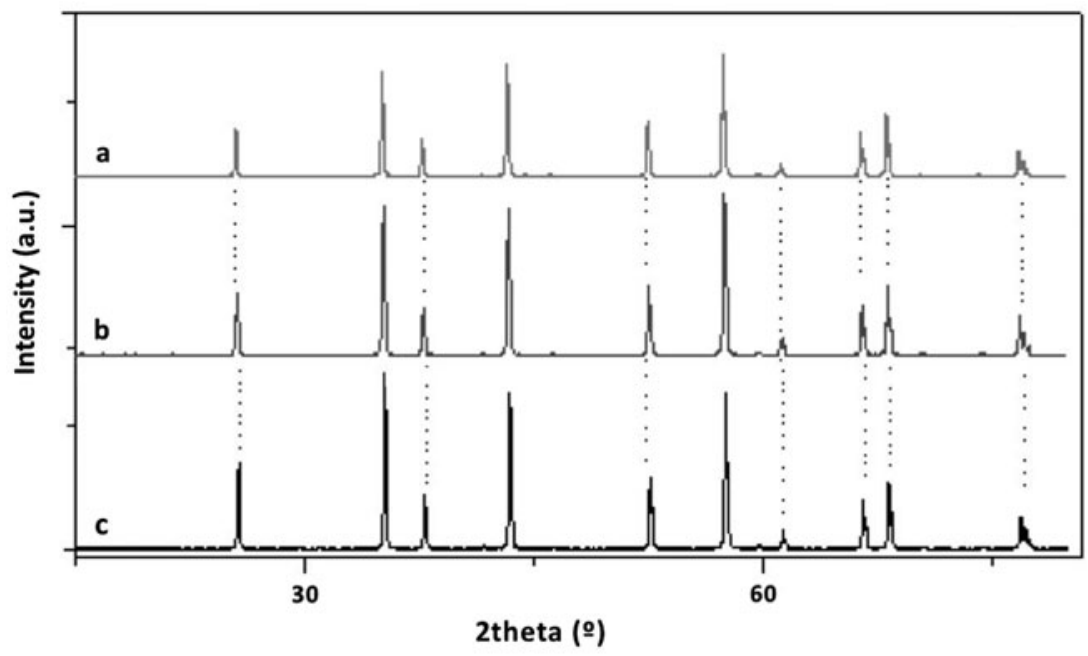

Fig. 1. XRD of the powder $\alpha$-alumina (a) and $\alpha$-alumina composite membrane sintered for $2 \mathrm{~h}$ at $1,450^{\circ} \mathrm{C}(\mathrm{b})$, and $1,475^{\circ} \mathrm{C}(\mathrm{c})$. Note: Values correspond to the diffraction peaks, expressed as degrees.

substrate sintered at lower temperature $\left(1,450{ }^{\circ} \mathrm{C}\right)$ shows higher porous structure with an average porosity of $29.7 \%$ (Fig. 2(a)) and appear to be more consolidated, due to particles agglomeration that create a more dense ceramic body [21]. The membrane sintered at $1,475^{\circ} \mathrm{C}$ (Fig. 2(b)) shows a rougher morphological structure with a lower porosity $(25.5 \%)$. The average pore size is similar in both membranes $(0.4 \mu \mathrm{m})$ with a slight difference in pore distribution $0.025-1.7 \mu \mathrm{m}$ at $1,475^{\circ} \mathrm{C}$ and $0.025-2.0 \mu \mathrm{m}$ at $1,450{ }^{\circ} \mathrm{C}$. The pore size is in accordance with the commercial microfiltration membranes for wastewater treatment ranging from 0.2 to $5 \mu \mathrm{m}$. The chemical composition of the $\alpha$-alumina membranes was obtained by energy-dispersive X-ray fluorescence spectroscopy (EDX) measurements. The membranes are mainly constituted by $\mathrm{Al}_{2} \mathrm{O}_{3}(97.65 \%)$ with small amounts of $\mathrm{SO}_{3}(1.16 \%), \mathrm{SiO}(0.81 \%), \mathrm{P}_{2} \mathrm{O}_{5}$ $(0.19 \%)$, and other impurities $(0.19 \%)$. The observed sulfur impurities are low enough to not create inhomogeneous volume changes or membrane buckle on heating as previously observed in other works [22]. No organic residues was detected in the EDX analysis, confirming that the first stage of the $2 \mathrm{~h}$ sintering from 32 to $500^{\circ} \mathrm{C}$ with a heating rate of $3^{\circ} \mathrm{C} \mathrm{min}{ }^{-1}$ was effective in burning out the binders [23]. The second densification stage of the ceramic bodies up to $1,475^{\circ} \mathrm{C}$ was performed with a heating rate of $5^{\circ} \mathrm{C} \mathrm{min}^{-1}$ ).

The alumina membrane was prepared with PVA as binder to increase strength and viscosity of the alumina network. It was reported that the average pore 

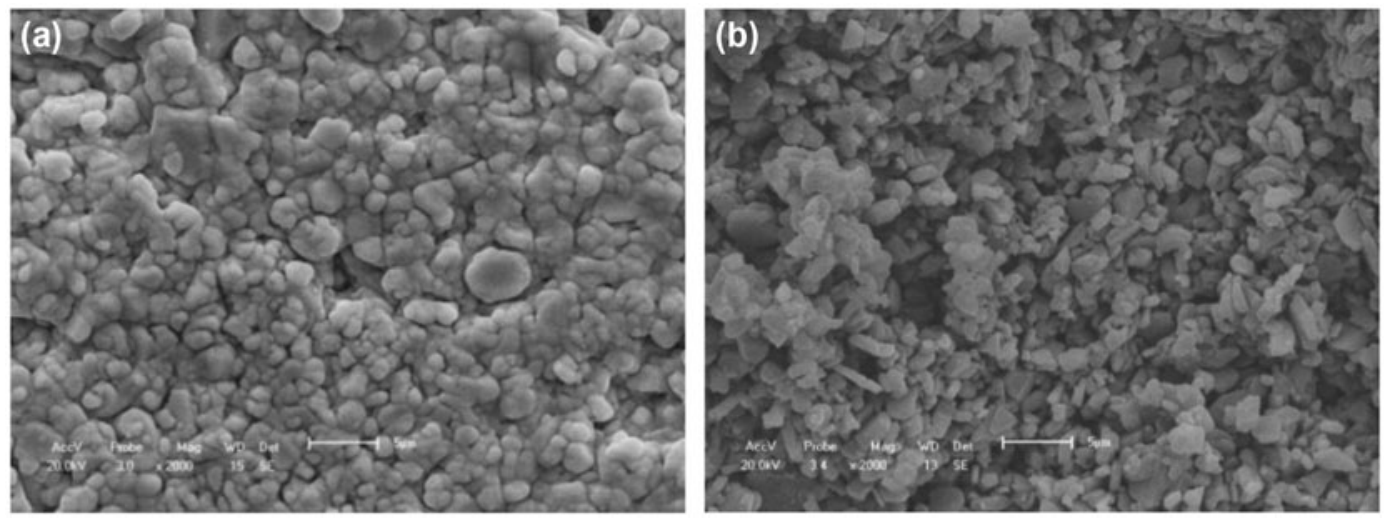

Fig. 2. SEM images (x2000) of the surface of $\alpha$-alumina composite membrane sintered at $1,450^{\circ} \mathrm{C}(\mathrm{a})$ and $1,475{ }^{\circ} \mathrm{C}(\mathrm{b})$ for $2 \mathrm{~h}$.

size of pure alumina membranes sintered with PVA increases sharply after sintering at temperatures higher than $1,000^{\circ} \mathrm{C}$. This increase in the pore size is accompanied up to $1,200^{\circ} \mathrm{C}$ by the phase transformation from $\gamma$-alumina via transition alumina to $\alpha$-alumina. The addition of PVA could reduce the thermal stability of the alumina membranes at high temperatures; however it prevents the formation of cracking, reducing the stress during the drying process and enhances the strength and viscosity of the network [24]. Another polymer with relatively high polarity, viscosity, and water miscibility such as EG was added to improve the wetting of alumina and to reduce the friction between particles during compression [25].

The DSC curve shows a slightly broad exothermic peak centered at $1,230^{\circ} \mathrm{C}$ that is immediately followed by an endothermic event (Fig. 3). This behavior, without noticeable weight variation in the TGA curve, is attributed to the phase transformation of the $\alpha$-alumina crystallization [26]. This event is irreversible and does not reappear in consecutive heating cycles as previously observed by Kirchner et al. [22]. TGA analysis shows that the degradation takes place in three well-differentiated steps (Fig. 3). In the first step, the membrane displays an initial weight loss up to $150^{\circ} \mathrm{C}$ attributed to the evaporation of free water/alcohol and to the dissociation of organic additives from the sample. Above this temperature, the weight remains relatively constant until a second phase, starting at around $250^{\circ} \mathrm{C}$ and continues till $300^{\circ} \mathrm{C}$, attributed to PVA side-chain decomposition with a major weight loss of about $3 \%$. Then, a slow and progressive carbonization phase, due to the decomposition of the main chain of PVA, is observed as the temperature increased further. From $530^{\circ} \mathrm{C}$, a maximum weight loss of $5 \%$ is reached and no further weight loss can be observed [27]. This last weight loss is concomitant to an exothermic event in the DSC curve due to the decomposition of the organic groups in the composite material [28].

The average pore size and mechanical resistance of both membranes sintered at 1,450 and $1,475^{\circ} \mathrm{C}$ was very close, however the membrane sintered at $1,450^{\circ} \mathrm{C}$ for $2 \mathrm{~h}$ showed better pore size distribution, lower burning linear contraction, and higher WA with higher potential selectivity and efficiency in the removal of indigo dye from the effluents. Thus, it was adopted for the microfiltration tests. All microfiltration experiments were conducted at room temperature and under a pressure of 1 bar obtaining a stable flux after few minutes of operation. The permeate flux of the used effluent was about $150 \mathrm{~L} \mathrm{~h} \mathrm{~m}^{-2}$. This result is in agreement with permeate fluxes of alumina microfiltration membranes reported in literature [29]. The conductivity of the filtrate shows a reduction of about $80 \%$, due to an efficient removal of the salts in the wastewater (Table 2). The membrane ability to significantly reduce conductivity is quite surprising since microfiltration process is not efficient in removing soluble salts from wastewaters.

A pretreatment of the effluent was necessary because of the high alkalinity of the raw effluent $(\mathrm{pH}$ of 10.6). The $\mathrm{pH}$ of the pretreated effluent ( $\mathrm{pH}$ of 4.6) after filtration tends to neutrality ( $\mathrm{pH}$ of 6.4). Turbidity, which is a good indicator on the reduction of pollutants in the effluent, is reduced by $94.5 \%$ removing almost all the colloidal particles or suspended solids. This is confirmed by the concomitant reduction of suspended and dissolved solids that show values of 92.5 and $89.3 \%$, respectively. Considering that this is a microfiltration performed at $1 \mathrm{bar}$, the reduction of COD is unexpectedly elevated reaching $74 \%$, whereas $\mathrm{TP}$ removal efficiency is $91.5 \%$. COD reduction is clearly influenced by $\mathrm{pH}$. The pretreatment lowering of the 


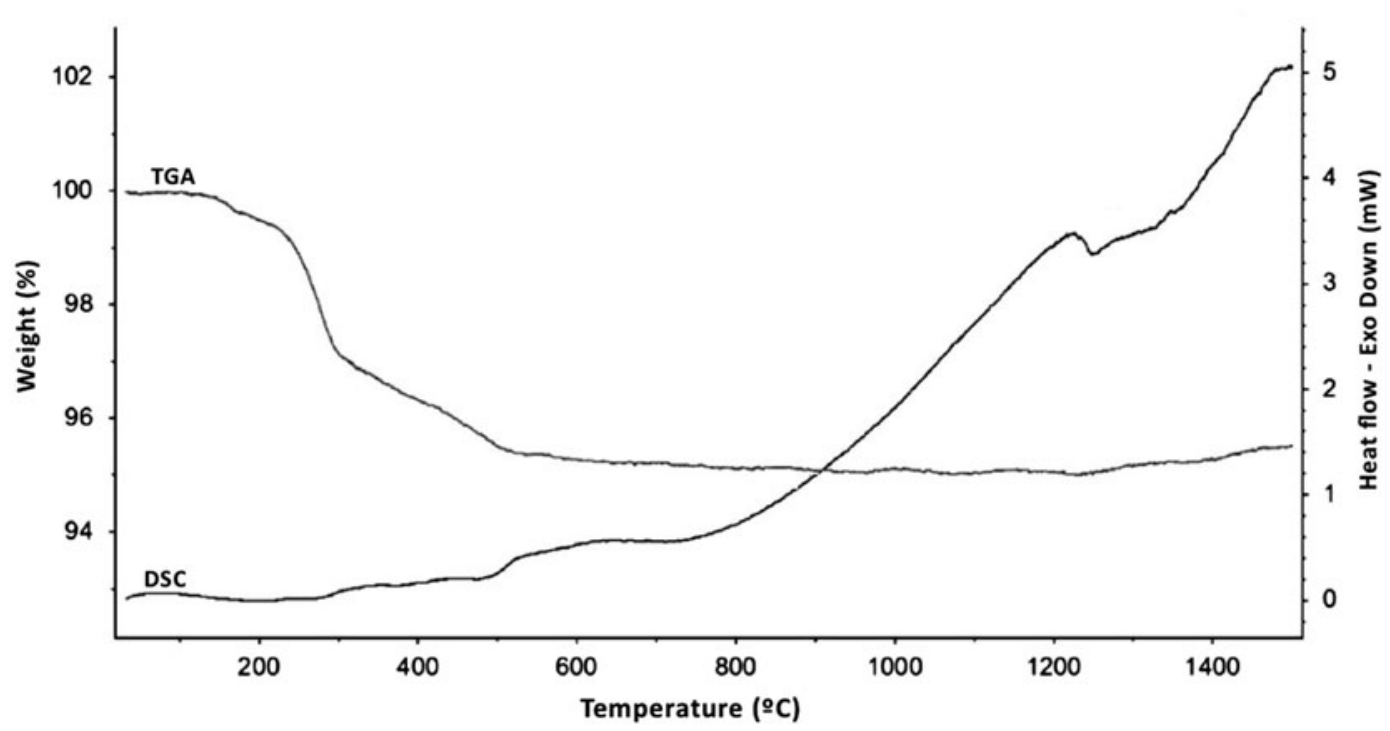

Fig. 3. TGA and DSC analyses of $\alpha$-alumina composite membranes from 25 to $1,200^{\circ} \mathrm{C}$, performed at a heating rate of $10^{\circ} \mathrm{C} \mathrm{min^{-1 }}$, in an argon atmosphere with a flow rate of $70 \mathrm{ml} \mathrm{min}$.

Table 2

Physicochemical parameters and metal concentrations of the textile effluent before and after filtration using the membranes sintered at $1,450^{\circ} \mathrm{C}$ for $2 \mathrm{~h}$. Data are means \pm standard deviations $(n=3)$

\begin{tabular}{llll}
\hline Parameters & Pretreated effluent & Filtrate effluent & Efficiency $(\%)$ \\
\hline $\mathrm{pH}$ & $4.62 \pm 0.50$ & $6.42 \pm 0.16$ & - \\
Temperature & $23.70 \pm 0.87$ & $36.20 \pm 1.15$ & - \\
Cadmium (mg/l) & $0.02 \pm 0.02$ & $0.03 \pm 0.02$ & - \\
Lead (mg/l) & $0.33 \pm 0.02$ & $0.16 \pm 0.01$ & 51.5 \\
Zinc (mg/l) & $0.42 \pm 0.16$ & $0.15 \pm 0.15$ & 64.3 \\
Iron (mg/l) & $1.91 \pm 1.10$ & $0.54 \pm 0.32$ & 71.7 \\
Chromium (mg/l) & $0.08 \pm 0.02$ & $0.03 \pm 0.01$ & 56.2 \\
Copper (mg/l) & $0.07 \pm 0.02$ & $0.03 \pm 0.01$ & 57.1 \\
Manganese (mg/l) & $0.33 \pm 0.05$ & $0.12 \pm 0.04$ & 63.6 \\
Nickel (mg/l) & $0.41 \pm 0.07$ & $0.18 \pm 0.05$ & 56.1 \\
Total phosphorous (mg/l) & $0.87 \pm 0.77$ & $0.07 \pm 0.02$ & 91.5 \\
Electrical conductivity ( $\mu$ S/cm) & $5,205.51 \pm 998.77$ & $960.05 \pm 20.60$ & 81.6 \\
Color (mg Pt-Co/L) & $349.78 \pm 52.91$ & $38.42 \pm 6.81$ & 89.0 \\
Turbidity (NTU) & $169.17 \pm 34.23$ & $9.23 \pm 1.18$ & 94.5 \\
Suspended solids (mg/l) & $130.13 \pm 21.45$ & $9.78 \pm 1.41$ & 92.5 \\
Dissolved solids (mg/l) & $5,727.63 \pm 834.32$ & $613.59 \pm 22.78$ & 89.3 \\
Oil and grease (mg/l) & $3.95 \pm 1.76$ & $3.36 \pm 1.01$ & \\
COD (mg/l) & $1,368.48 \pm 587.11$ & $372.18 \pm 39.83$ & 72.8 \\
\hline
\end{tabular}

$\mathrm{pH}$ in the effluent improved the number of $\mathrm{H}^{+}$ions in solution favoring a charge neutralization phenomenon, which in turn favored the reduction of COD of effluent [30]. Spectral analysis of the effluent at $420 \mathrm{~nm}$ shows that the discoloration is almost complete reaching $89 \%$. This high value could be explained by favorable molecular interactions of auxiliaries and mineral salt on dye removal efficiency [31]. However, the con- comitant high reduction of color and COD in the effluent is rarely observed in literature with this type of membranes. Only UF and nanofiltration membranes are usually able to remove more than $90 \%$ of color, turbidity, TDS, and COD [29,32]. No significant reduction of oil and grease content is observed. However, its content is very low. It is known that the suspended solids adsorb the oil, break up the oil layer, and act as 
a dynamic or secondary membrane which reduces fouling of the underlying primary membrane [33].

The rejection is due to the strong interactions developed between the multivalent cations and the positively charged membrane. The rejection rates depend strongly on the $\mathrm{pH}$ of the filtered solution according to the modification of the membrane surface charge, which is positively charged at the acidic $\mathrm{pH}$ values of the pretreated effluent. This prevents metal precipitation and repulses outside of the pore, where the positively charged multivalent co-ions lead to good rejection values [34]. The rejection obtained for the filtration of metal cations (Table 2) is in average $60 \%$, which proves the great efficiency of these lowcost membranes for textile wastewater treatment.

\section{Conclusion}

The ceramic membranes developed in this study demonstrate extremely high chemical and physical stability, with outstanding separation characteristics. The developed membranes show simultaneous high reduction of turbidity, COD, color, metals, suspended, and dissolved solids removal $(94.5,74,90,60,92.5$, and $89.3 \%$, respectively), confirming the feasibility of using porous alumina ceramic membranes in advanced treatment of industrial wastewater with high contaminant load. The results obtained in this work are comparable with UF systems operating at higher pressures and energy consumption. Despite their higher cost compared with the standard commercial polymer membranes, it is clear that the obtained microfiltration membranes with their superior thermal and chemical resistance have a great potential for the recovery of low-soluble textile dyes, such as indigo with higher energy and cost savings avoiding the use of highpressure filtration systems.

\section{Acknowledgment}

Andrea Zille (C2011- UMINHO-2C2T-01) acknowledges funding from Programa Compromisso para a Ciência 2008, Portugal.

\section{References}

[1] F.R. Oliveira, A. Zille, A.P. Souto, Dyeing mechanism and optimization of polyamide 6,6 functionalized with double barrier discharge (DBD) plasma in air, Appl. Surf. Sci. 293 (2014) 177-186.

[2] S. Barredo-Damas, M.I. Alcaina-Miranda, A. Bes-Piá, M.I. Iborra-Clar, A. Iborra-Clar, J.A. Mendoza-Roca, Ceramic membrane behavior in textile wastewater ultrafiltration, Desalination 250 (2010) 623-628.
[3] S.K.A. Solmaz, A. Birgul, G.E. Ustun, T. Yonar, Colour and COD removal from textile effluent by coagulation and advanced oxidation processes, Color. Technol. 122 (2006) 102-109.

[4] I. Oller, S. Malato, J.A. Sánchez-Pérez, Combination of advanced oxidation processes and biological treatments for wastewater decontamination-A review, Sci. Total Environ. 409 (2011) 4141-4166.

[5] H. Lin, W. Gao, F. Meng, B.-Q. Liao, K.-T. Leung, L. Zhao, J. Chen, H. Hong, Membrane bioreactors for industrial wastewater treatment: A critical review, Crit. Rev. Env. Sci. Technol. 42 (2012) 677-740.

[6] A.K. Verma, R.R. Dash, P. Bhunia, A review on chemical coagulation/flocculation technologies for removal of colour from textile wastewaters, J. Environ. Manage. 93 (2012) 154-168.

[7] K. Singh, S. Arora, Removal of synthetic textile dyes from wastewaters: A critical review on present treatment technologies, Crit. Rev. Env. Sci. Technol. 41 (2011) 807-878.

[8] C. Fersi, L. Gzara, M. Dhahbi, Treatment of textile effluents by membrane technologies, Desalination 185 (2005) 399-409.

[9] S. Chakraborty, S. De, J.K. Basu, S. DasGupta, Treatment of a textile effluent: Application of a combination method involving adsorption and nanofiltration, Desalination 174 (2005) 73-85.

[10] Y.I. Komolikov, L.A. Blaginina, Technology of ceramic micro and ultrafiltration membranes (review), Refract. Ind. Ceram. 43 (2002) 181-187.

[11] Z.B. Wang, Q.Q. Ge, J. Shao, Y.S. Yan, High performance zeolite LTA pervaporation membranes on ceramic hollow fibers by dipcoating-wiping seed deposition, J. Am. Chem. Soc. 131 (2009) 6910-6911.

[12] S. Muthukumaran, K. Baskaran, Comparison of the performance of ceramic microfiltration and ultrafiltration membranes in the reclamation and reuse of secondary wastewater, Desalin. Water Treat. 52 (2014) 670-677.

[13] G. Masmoudi, R. Trabelsi, E. Ellouze, R.B. Amar, New treatment at source approach using combination of microfiltration and nanofiltration for dyeing effluents reuse, Int. J. Environ. Sci. Technol. 11 (2013) 1007-1016.

[14] N. Uzal, L. Yilmaz, U. Yetis, Microfiltration/ultrafiltration as pretreatment for reclamation of rinsing waters of indigo dyeing, Desalination 240 (2009) 198-208.

[15] R.C.O. Lima, H.L. Lira, G.A. Neves, M.C. Silva, K.B. França, Use of ceramic membrane for indigo separation in effluent from textile industry, Mater. Sci. Forum 798-799 (2014) 537-541.

[16] B.E.E. Hegazy, H.A. Fouad, A.M. Hassanain, Brick manufacturing from water treatment sludge and rice husk ash, Aust. J. Basic Appl. Sci. 6 (2012) 453-461.

[17] I.N. Bhattacharya, S.C. Das, P.S. Mukherjee, S. Paul, P.K. Mitra, Thermal decomposition of precipitated fine aluminium trihydroxide, Scand. J. Metall. 33 (2004) 211-219.

[18] Y. Dong, S. Hampshire, J.-e. Zhou, B. Lin, Z. Ji, X. Zhang, G. Meng, Recycling of fly ash for preparing porous mullite membrane supports with titania addition, J. Hazard. Mater. 180 (2010) 173-180.

[19] S. Gopalakrishnan, T. Yamaguchi, S.-i. Nakao, Permeation properties of templated and template-free ZSM-5 membranes, J. Membr. Sci. 274 (2006) 102-107. 
[20] W.L. Suchanek, J.M. Garcés, Hydrothermal synthesis of novel alpha alumina nano-materials with controlled morphologies and high thermal stabilities, Cryst. Eng. Comm. 12 (2010) 2996.

[21] B.K. Nandi, R. Uppaluri, M.K. Purkait, Preparation and characterization of low cost ceramic membranes for micro-filtration applications, Appl. Clay Sci. 42 (2008) 102-110.

[22] A. Kirchner, K.J.D. MacKenzie, I.W.M. Brown, T. Kemmitt, M.E. Bowden, Structural characterisation of heat-treated anodic alumina membranes prepared using a simplified fabrication process, J. Membr. Sci. 287 (2007) 264-270.

[23] N.F. Ismail, Z. Harun, N.A. Badarulzaman, A comparative study of double layers $\mathrm{Al}_{2} \mathrm{O}_{3} / \mathrm{Al}_{2} \mathrm{O}_{3}$ and $\mathrm{Al}_{2} \mathrm{O}_{3}$ / $\mathrm{SiO}_{2}$ prepared by microwave and natural drying, Int. J. Integr. Eng. 4 (2013) 16-21.

[24] Y.S. Lin, A.J. Burggraaf, Preparation and characterization of high-temperature thermally stable alumina composite membrane, J. Am. Ceram. Soc. 74 (1991) 219-224.

[25] S. Ananthakumar, P. Manohar, K.G.K. Warrier, Effect of boehmite and organic binders on extrusion of alumina, Ceram. Int. 30 (2004) 837-842.

[26] M.M. Martín-Ruiz, L.A. Pérez-Maqueda, T. Cordero, V. Balek, J. Subrt, N. Murafa, J. Pascual-Cosp, High surface area $\alpha$-alumina preparation by using urban waste, Ceram. Int. 35 (2009) 2111-2117.

[27] P. Monash, G. Pugazhenthi, Development of ceramic supports derived from low-cost raw materials for membrane applications and its optimization based on sintering temperature, Int. J. Appl. Ceram. Technol. 8 (2011) 227-238.

[28] C. Jing, X. Xu, J. Hou, Synthesis of sub-micro-sized solid alpha alumina fibers with smooth surfaces by sol-gel method, J. Sol-Gel Sci. Technol. 45 (2007) 109113.

[29] A. Majouli, S. Tahiri, S. Alami Younssi, H. Loukili, A. Albizane, Elaboration of new tubular ceramic membrane from local Moroccan Perlite for microfiltration process. Application to treatment of industrial wastewaters, Ceram. Int. 38 (2012) 4295-4303.

[30] P. Bhattacharya, S. Dutta, S. Ghosh, S. Vedajnananda, S. Bandyopadhyay, Crossflow microfiltration using ceramic membrane for treatment of sulphur black effluent from garment processing industry, Desalination 261 (2010) 67-72.

[31] K.M. Majewska-Nowak, Application of ceramic membranes for the separation of dye particles, Desalination 254 (2010) 185-191.

[32] H.P. Srivastava, G. Arthanareeswaran, N. Anantharaman, V.M. Starov, Performance of modified poly(vinylidene fluoride) membrane for textile wastewater ultrafiltration, Desalination 282 (2011) 87-94.

[33] J. Mueller, Y.W. Cen, R.H. Davis, Crossflow microfiltration of oily water, J. Membr. Sci. 129 (1997) 221-235.

[34] N. Saffaj, M. Persin, S.A. Younssi, A. Albizane, M. Bouhria, H. Loukili, H. Dach, A. Larbot, Removal of salts and dyes by low $\mathrm{ZnAl}_{2} \mathrm{O}_{4}-\mathrm{TiO}_{2}$ ultrafiltration membrane deposited on support made from raw clay, Sep. Purif. Technol. 47 (2005) 36-42. 